\title{
Perancangan Sistem Informasi Rawat Jalan Pada Klinik Dr. Sarwoko PasarkemisTangerang
}

\author{
Putri Fitri Astuti ${ }^{1}$, Asep Sayfulloh ${ }^{2}$, Hanggoro Aji Al Kautsar ${ }^{3}$, Sujiliani Heristian ${ }^{4}$ \\ Badariatul Lailiah $^{5}$, Rabiatus Sa'adah ${ }^{6}$ \\ Universitas Bina Sarana Informatika \\ ${ }^{1}$ putrifitriastuti6722@gmail.com, ${ }^{2}$ Asep.alo@bsi.ac.id, ${ }^{3}$ Hanggoro.hgr@bsi.ac.id, ${ }^{4}$ Sujiliani.she@ bsi.ac.id, \\ 5Badariatul.bdl@bsi.ac.id, ${ }^{5}$ Rabiatus.rbh@bsi.ac.id

\begin{tabular}{ccc}
\hline Diterima & Direvisi & Disetujui \\
$15-12-2019$ & $16-12-2019$ & $17-12-2019$ \\
\hline
\end{tabular}

\begin{abstract}
Abstrak - Pada akhir abad ini. Kemajuan komputer sudah sangat pesat dan cepat perkembangannya, sehingga segala sesuatunya dibuat apapun hampir semua membutuhkan bantuan sistem terkomputerisasi. Saat ini mungkin hamper tidak ada yang tahu adanya komputer dikehidupan kita, terlebih lagi pada pelayanan kesehatan dan sangat tergantung dengan sistem komputerisasi. Klinik Dr. Sarwoko sangat memerlukan sekali sebuah sistem informasi yang dapat membantu kinerja klinik dan memberikan kemudahan bagi para pasien, khususnya administrasi sebagai pengguna dalam sistem tersebut. Unutk itulah saya sebagai penulis mencoba membuat Tugas Akhir dengan judul mengenai Perancangan Sistem Informasi Rawat Jalan Pada Klinik Dr. Sarwoko.Sebagian besar pasien yang berada di klinik ini adalah pasien yang memiliki perekonomian menengah kebawah, termasuk kaum dhuafa yang berada di daerah-daerah pelosok kabupaten Tangerang, khususnya daerah pasarkemis dan sekitarnya. Untuk itu dengan adanya sistem rawat jalan atau sebuah sistem pendukung untuk administrasi yang merupakan sebuah solusi yang terbaik untuk memecahkan permasalahan pada pembuatan laporan administrasi yang cenderung lama dan besar kemungkinan kesalahan, serta dengan program ini dapat tercapai suatu kegiatan yang efektif dan efisien dalam menunjang aktifitas pada klinik ini. Oleh karena itu dengan sistem ini dalam pembuatan laporan rawat jalan agar berjalan lebih efektif dan efisien. Serta sistem in lebih kondusif dari pada sistem manual yang terdahulu.
\end{abstract}

Kata Kunci: Perancangan Sistem, Rawat Jalan,Klinik Dr. Sarwoko

\section{PENDAHULUAN}

Klinik merupakan fasilitas pelayanan kesehatan yang menyelenggarakan pelayanan kesehatan perorangan yang menyediakan pelayanan medis dasar atau spesialistik.

Klinik yang mulai berkembang dalam sistem informasi menjadi sangat mendukung pada klinik, baik buruknya sebuah pelayanan klinik akan dinilai dari sistemnya. Maka dibutuhkan sebuah sistem informasi yang sangat mendukung ada sistem tersebut.

Pada Klinik dr. Sarwoko sistem yang digunakan masih menggunakan sistem manual, baik dalam pendaftaran pasien, maupun data diagnosa pasien. Terkadang pasien yang datang hanya mengandalkan ingatan mereka mengenai kapan terakhir mereka datang dan cocok dengan obat yang di konsumsinya, ini menjadi salah satu masalah yang timbul dalam pencarian data pasien tersebut. Karena data tersebut masih ditulis secara manual di buku besar dan bukan hanya satu pegawai, tetapi tulisan tangan beberapa pegawai sangat dapat memungkinkan pada saat proses dilakukan kesalahan atau terjadi sangat lambat pada prosesnya. Berdasarkan hal tersebut penulis mengambil sebuah judul : "Perancangan Sistem Informasi Rawat Jalan Pada Klinik Dr. Sarwoko".

\section{METODE PENELITIAN}

1. Metode pengembangan perangkat lunak

Menurut Rosa dan Shalahuddin (2016:28) “Model SDLC air terjun (waterfall) sering juga disebut model sekuensial linier (sequential linear) atau alur hidup klasik (classic life cycle). Model air terjun menyediakan pendekatan alur hidup perangkat lunak secara sekuensial atau terurut dimulai dari analisis, desain, pengodean, pengujian, dan tahap pendukung (support)".

2. Teknik Pengumpulan data

Agar dapat menunjang dan membantu pembuatan penulisan Tugas Akhir ini, sehingga dapat menghasilkan informasi yang lebih baik dan akurat. Maka penulis menggunakan tiga metode pengumpulan data, yaitu :

a. Metode Pengamatan (Observation )

Metode ini adalah metode paling sering dilakukan penulis untuk melakukan pengumpulan data. Yaitu pengamatan secara langsung mengenai proses pemeriksaan pasien baru. 
b. Metode Wawancara ( Interview)

Ialah sebuah metode yang berkaitan dengan komunikasi terhadap pihak yang terkait atau disebut juga dengan tanggung jawab. Khususnya pihak yang terkait pada penulisan tugas akhir ini adalah pemilik klinik dan staf pada klinik Dr. Sarwoko agar didapatkan informasi yang dibutuhkan secara lengkap dan terperinci.

c. Metode Studi Pustaka (Library)

Metode ini dilakukan penulis untuk memperoleh informasi dengan cara megumpulkan data-data keperpustakaan, yaitu dengan membaca dan mempelajari buku-buku pemrograman dan referensi yang berkaitan dengan meteri penulisan tugas akhir untuk mendapatkan penjelasan dan kemudahan atau gambaran mengenai materi dan logika-logika dalam penyusunan penulisan.

\section{Pengertian Sistem Informasi}

Menurut Loudon dalam jurnal (Akhmadsyukron, 2015) "Sistem Informasi (informasion System) secara teknis dapat didefinisikan sebagai sekumpulan komponen yang saling berhubungan mengumpulkan atau mendapatkan, memproses, menyimpan dan mendistribusikan informasi untuk menunjang pengambilan keputusan dan pengawasan dalam suatu organisasi”.

\section{UML (Unified Modeling Language)}

Menurut Fowler dalam jurnal (Akhmadsyukron, 2015) "Unifield Modelling Language (UML) adalah keluarga notasi grafis yang didukung oleh meta model tunggal, yang membantu pendeskripsian dan desain sistem perangkat lunak, khususnya sistem yang dibangun dengan menggunakan pemrograman berorientasi objek (oop)".

\section{a. Use case diagram}

Mendeskripsikan interaksi tipical antara para pengguna sistem dengan sistem itu sendiri, dengan memberi sebuah narasi tentang bagaimana sistem tersebut digunakan.

b. Activity diagram

Activity diagram adalah teknik untuk menggambarkan logika prosedural, proses bisnis dan proses kerja. Dalam beberapa hal, diagram ini memainkan

peran mirip sebuah diagram alir, tetapi perbedaan prinsip antara diagram ini dan notasi diagram alir adalah diagram ini mendukung behavior paralel.

c. Class diagram

Class diagram menggambarkan jenis objek dalam sistem dan berbagai jenis hubungan statis yang ada diantara mereka. Class diagram juga menunjukan sifat-sifat dan operasi dari sebuah kelas dan kendala yang berlaku untuk cara objek yang terhubung.

\section{d. Sequence diagram}

Sequence diagram menggambarkan interaksi antar objek didalam dan di sekitar sistem (termasuk pengguna,display, dan sebagainya) berupa message yang digambarkan terhadap waktu. Sequence diagram biasa digunakan untuk menggambarkan skenario atau langkahlangkah yang dilakukan sebagai respon dari sebuah event untuk menghasilkan output tertentu.

\section{HASIL DAN PEMBAHASAN}

\section{Analisa Sistem}

Berdasarkan pada sistem yang berjalan, terdapat beberapa masalah yang harus diselesaikan agar sistem rawat jalan pada klinik dr. sarwoko dapat berjalan dengan baik. Permasalahan yang terdapat pada sistem berjalan adalah :

1. Pendaftaran pasien masih ditulis dengan tangan oleh admin, sehingga sering tidak terbaca oleh admin lain saat bergantian menjaga.

2. Sering banyak data yang rusak atau hilang bahkan sering data yang didapat tidak akurat, hal ini menyulitkan dalam penyampaikan informasi

3. Keterlamatan pengolahan data.

Dari uraian permasalahan di atas maka penulis mencoba memberikan solusi dengan melakukan pembuatan perancangan sistem informasi agar dapat mengatasi masalah tersebut. Perancangan sistem informasi ini dilakukan dengan tujuan agar sistem dapat :

1. Melakukan input data lebih cepat agar pembuatan laporan tidak terlambat.

2. Mempermudah admin dalam mengelola proses pendaftaran pasien.

3. Mempermudah mengelola data pasien.

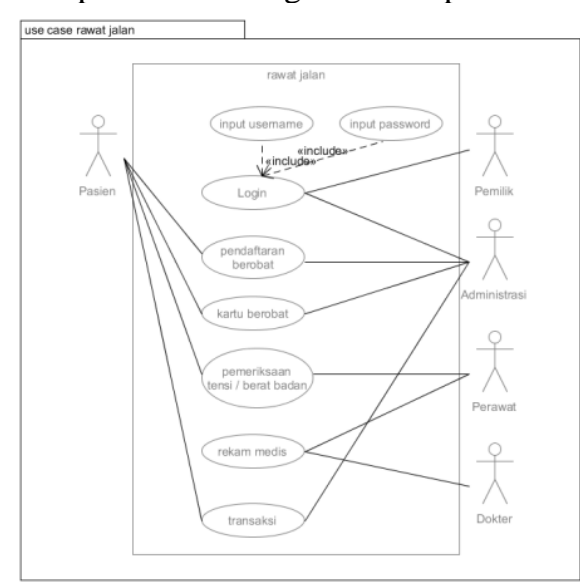

Gambar : 1. Digram Use Case Usulan 


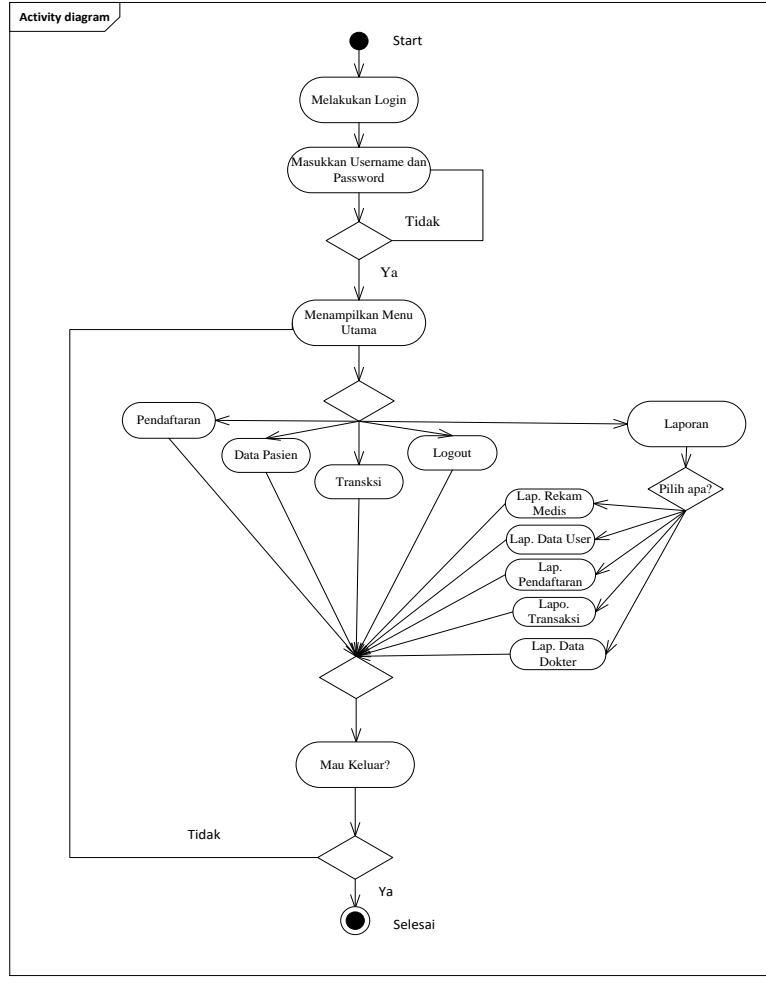

Gambar : 2. Digram Aktivitas

\section{Rancangan Prototype}

A. Tampilan Index Klinik

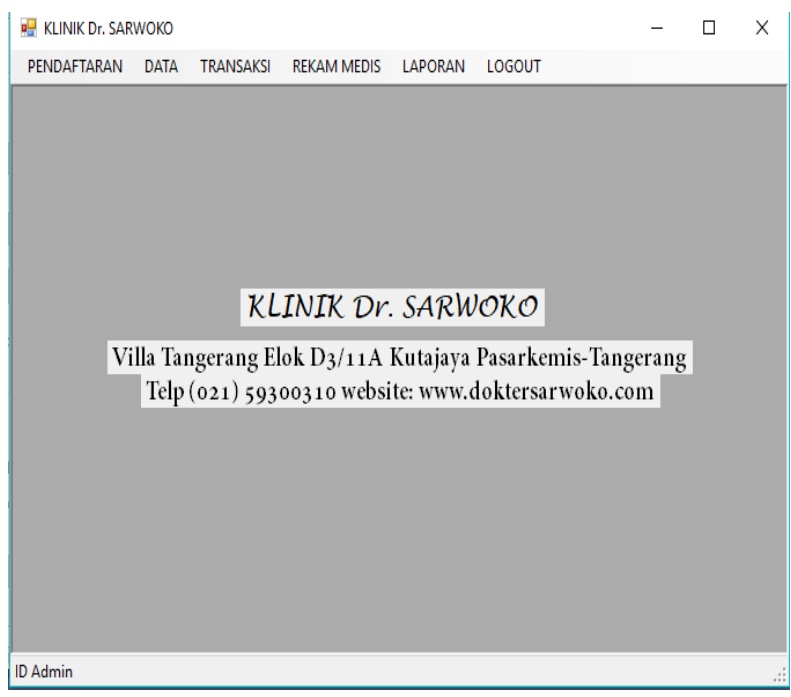

Gambar: 3. Tampilan Index
A. Tampilan Login User

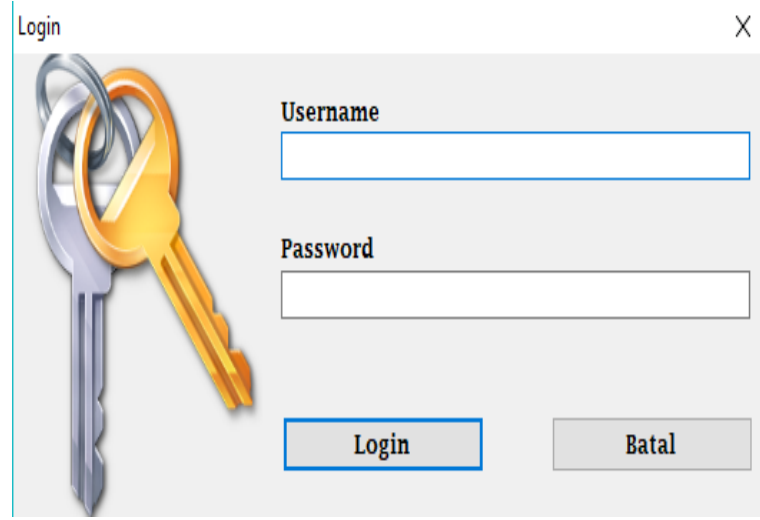

Gambar: 4. Tampilan Login User

C. Tampilan Splash

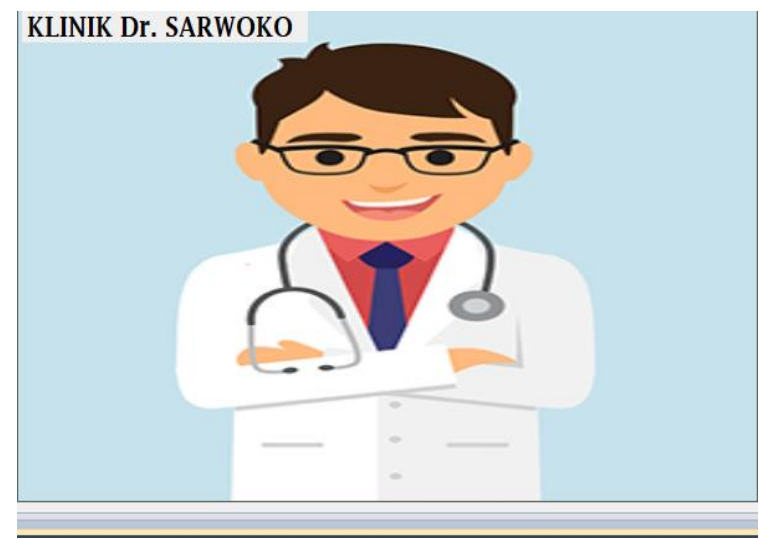

Gambar: 5. Tampilan Splash

D. Tampilan Pendaftaran Pasien

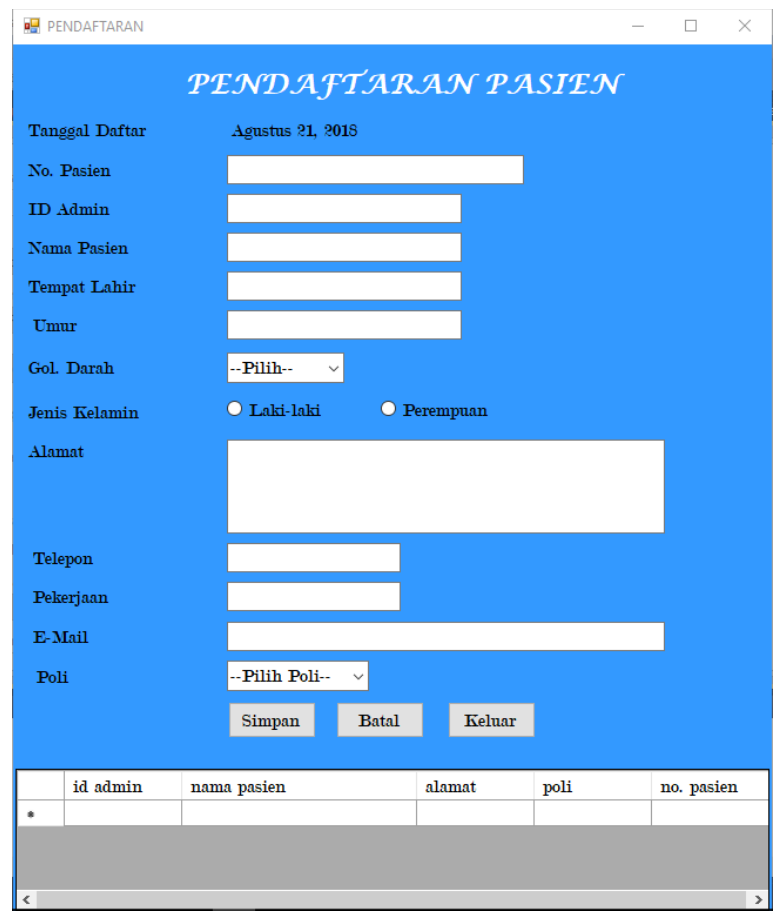

Gambar: 6. Tampilan Form Pendaftaran 
E. Tampilan Rekam Medis Pasien

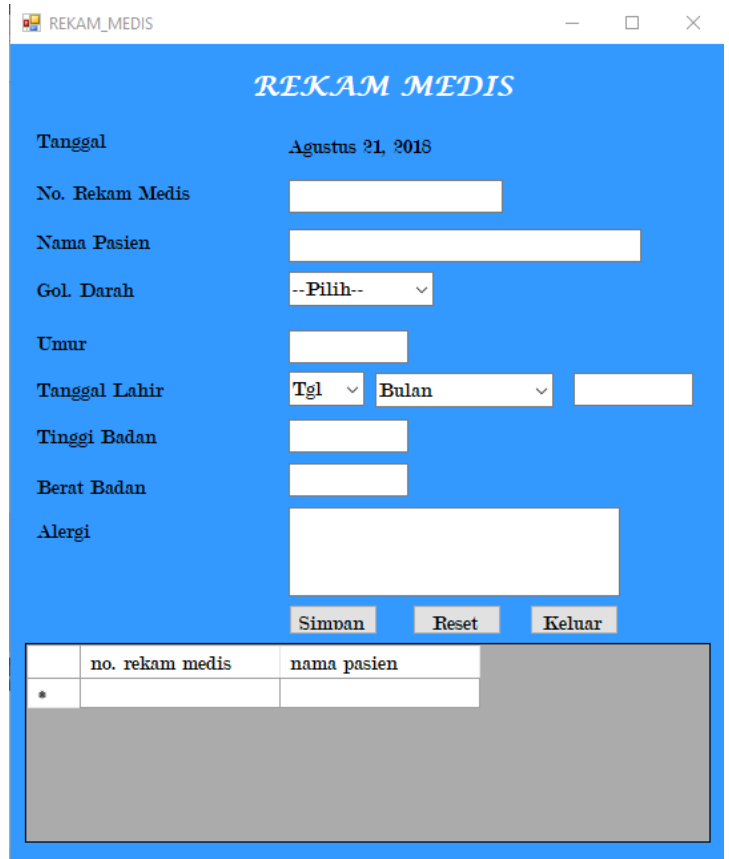

Gambar: 7. Tampilan Form Rekam Medis

F. Tampilan Transaksi

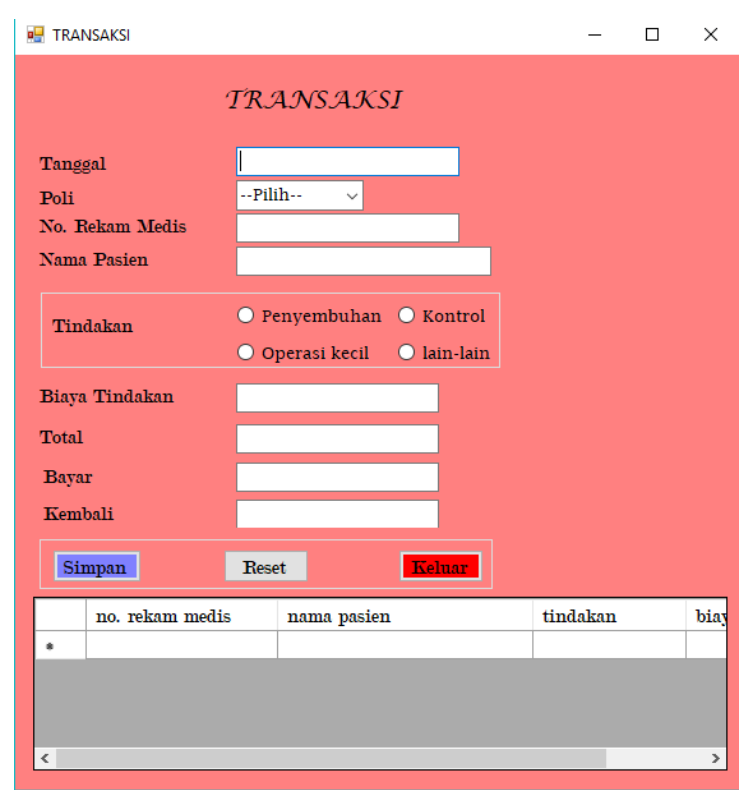

Gambar: 8. Tampilan Form Transaksi

\section{G. Tampilan Data User}

吅 DATA_USER

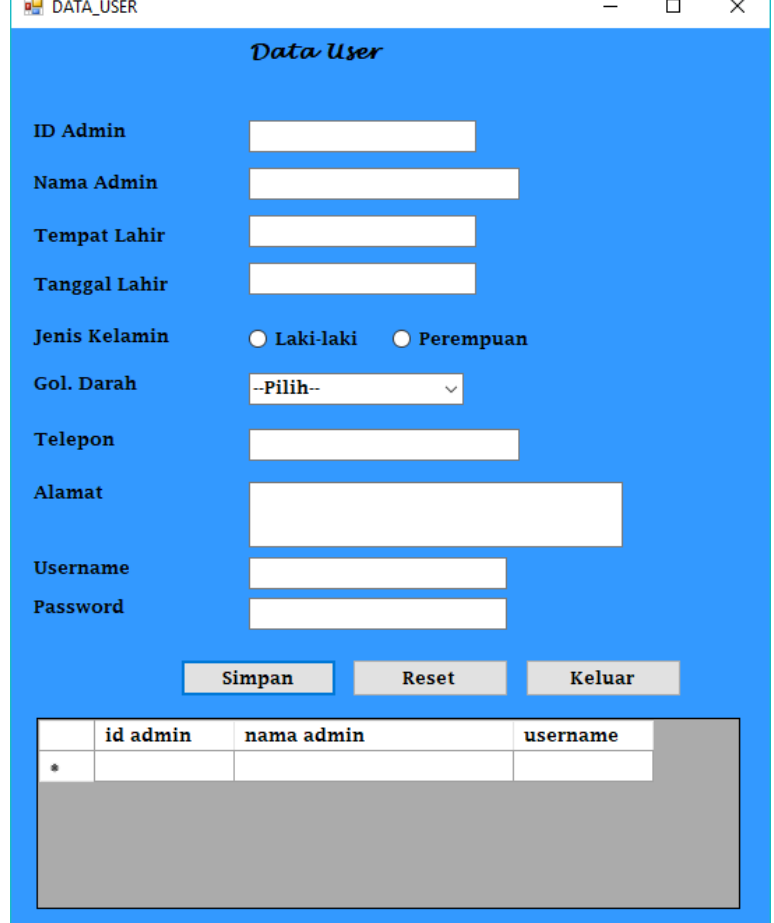

\section{Gambar: 9. Tampilan Form Input Data User}

H. Tampilan Data Dokter

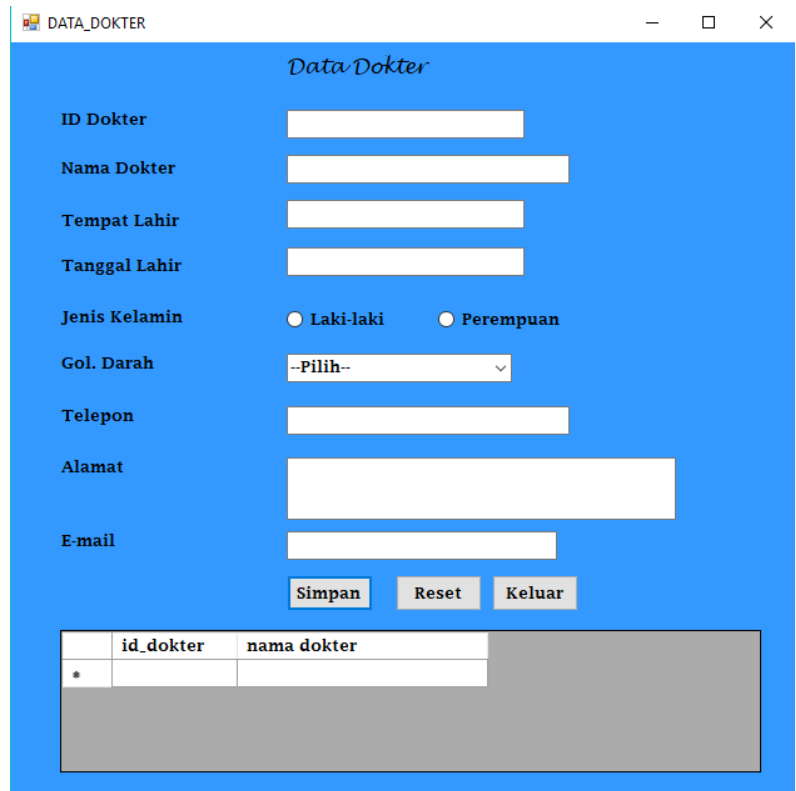

Gambar: 10. Tampilan Form Input Data Dokter 


\section{Tampilan Data Pasien}

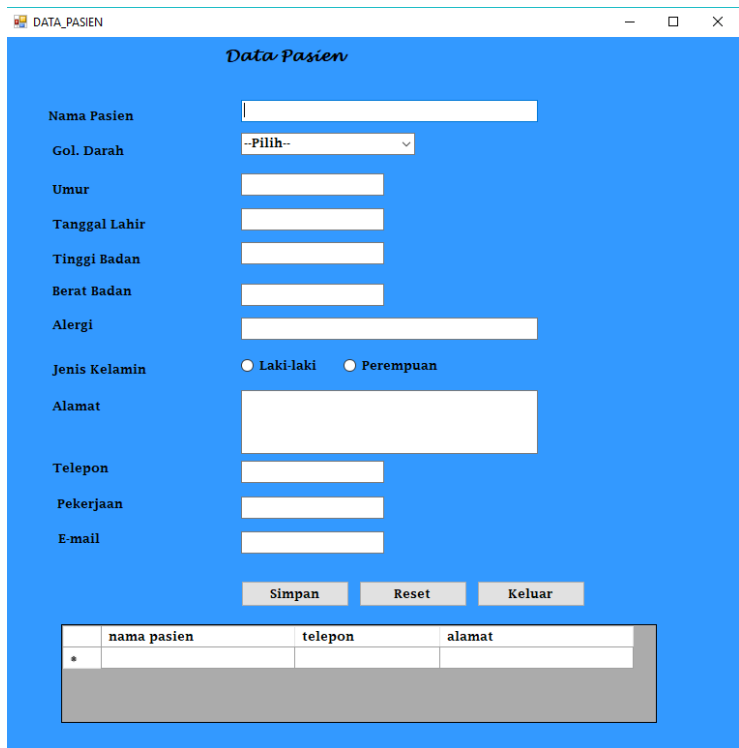

Gambar: 11. Tampilan Form Input Data Pasien

\section{KESIMPULAN}

Sistem komputerisasi dapat mempermudah dalam melakukan sistem administrasi rawat jalan serta Mempermudah dalam pembuatan laporan pendaftaran, laporan dokter, laporan data user, laporan transaksi dan laporan rekam medis.

\section{REFERENSI}

Akhmadsyukron. (2015). Perancangan Sistem Rawat Jalan Berasis web Pada Puskesmas Winog. Informatika, 3(1), 28-34.

Aminudin, N. (2016). Dasar Pemrograman Visual Basic. (E.Risanto,Ed.) (1st ed.). Yogyakarta: ANDI

Dermawan, J., \& Hartini, S. (2017). Implementasi Model Waterfall Pada Pengembangan Berbasis Web Pada Sekolah Dasar Al-Azhar Syifa Budi Jatibening, 19(2).

Fatmawati. (2016). Perancangan Sistem Informasi Pemesanan Katering Berbasis Web Pada Rumah Makan Tosuka Tangerang. Jurnal Teknik Komputer AMIK BSI, II(2), 33-41.

Shalahuddin, M. dan Rosa A.S. 2016. Rekayasa Perangkat Lunak. Informatika Bandung.

Supriyanta, \& Nisa, K. (2015). Perancangan Website Desa Wisata Karangrejo Sebagai Media Informasi dan Promosi. Bianglala Informatika, 3(1), 35-40.

Wibowo, H. R., \& Enterprise, J. (2014). Buku Pintar VB.NET. Jakarta: Pt. Elex Media Komputindo. 